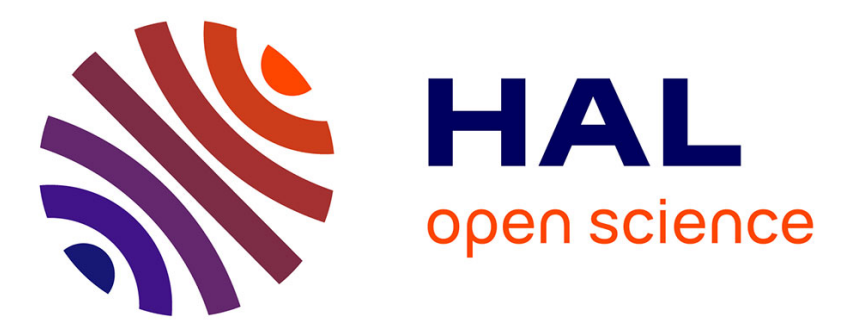

\title{
La fonction de l'endettement et de la justice dans le rapport seigneurial, ou la grâce comme contrainte (Franconie, XVe siècle)
}

\author{
Julien Demade
}

\section{To cite this version:}

Julien Demade. La fonction de l'endettement et de la justice dans le rapport seigneurial, ou la grâce comme contrainte (Franconie, XVe siècle). Dec 2006, pp.69-119. halshs-00120336v3

\section{HAL Id: halshs-00120336 \\ https://shs.hal.science/halshs-00120336v3}

Submitted on 21 Jun 2007

HAL is a multi-disciplinary open access archive for the deposit and dissemination of scientific research documents, whether they are published or not. The documents may come from teaching and research institutions in France or abroad, or from public or private research centers.
L'archive ouverte pluridisciplinaire HAL, est destinée au dépôt et à la diffusion de documents scientifiques de niveau recherche, publiés ou non, émanant des établissements d'enseignement et de recherche français ou étrangers, des laboratoires publics ou privés. 


\section{Graphique 1 : Rapport des arrérages cumulés aux redevances annuelles à Simonshofen}

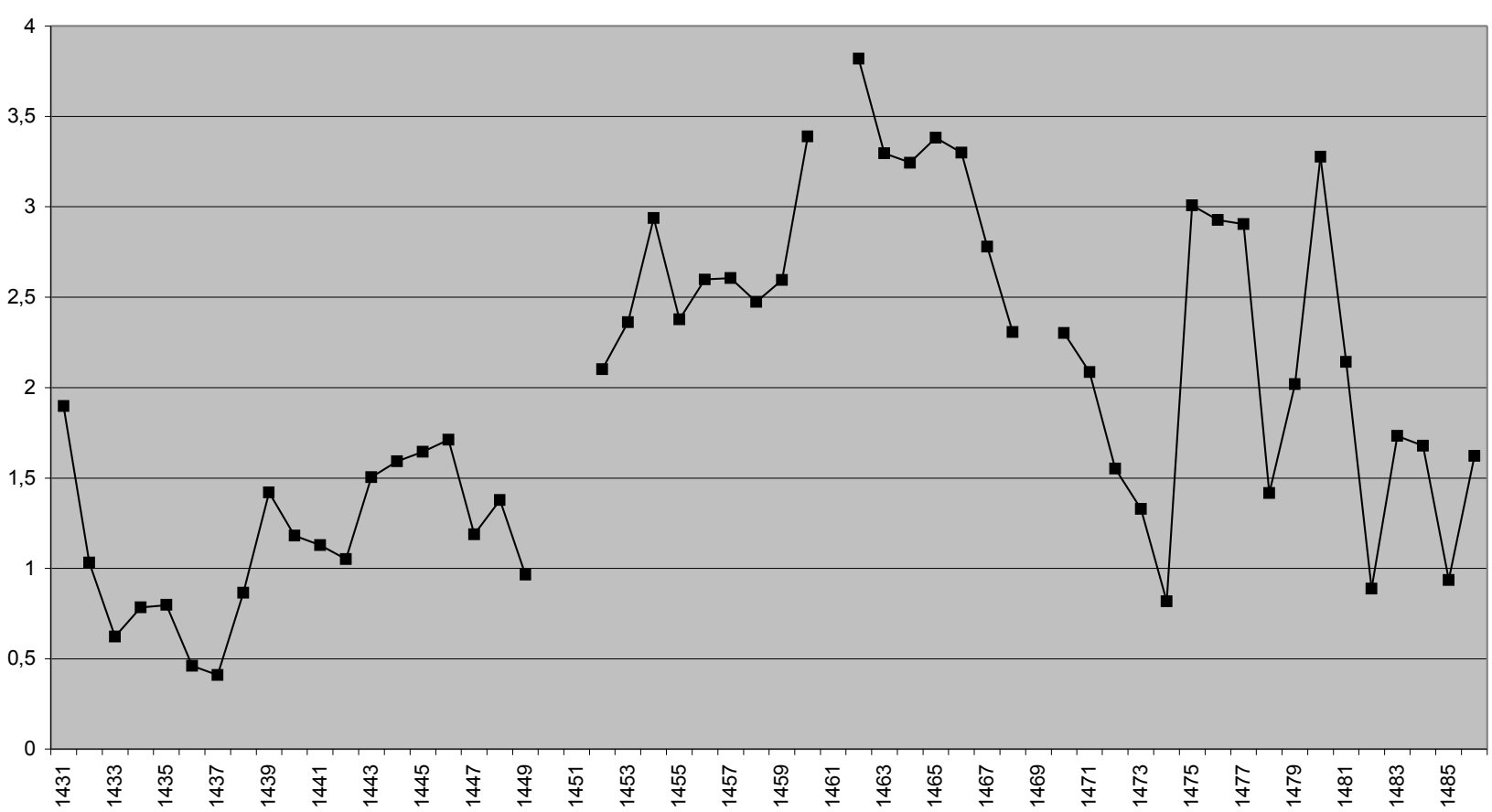

Graphique 2 : Les causes des mutations foncières à Simonshofen

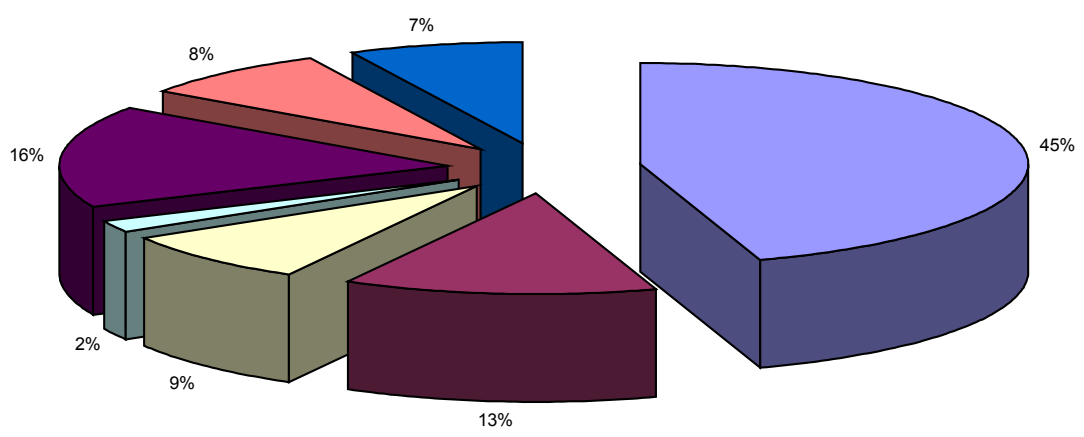

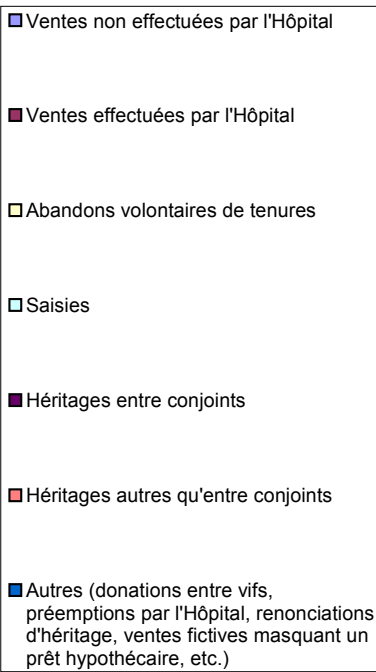


Graphique 3 : Arrérages de Fritz Hützelmeier (sans les arrérages repris d'Hans Loness), en \% de ses redevances annuelles

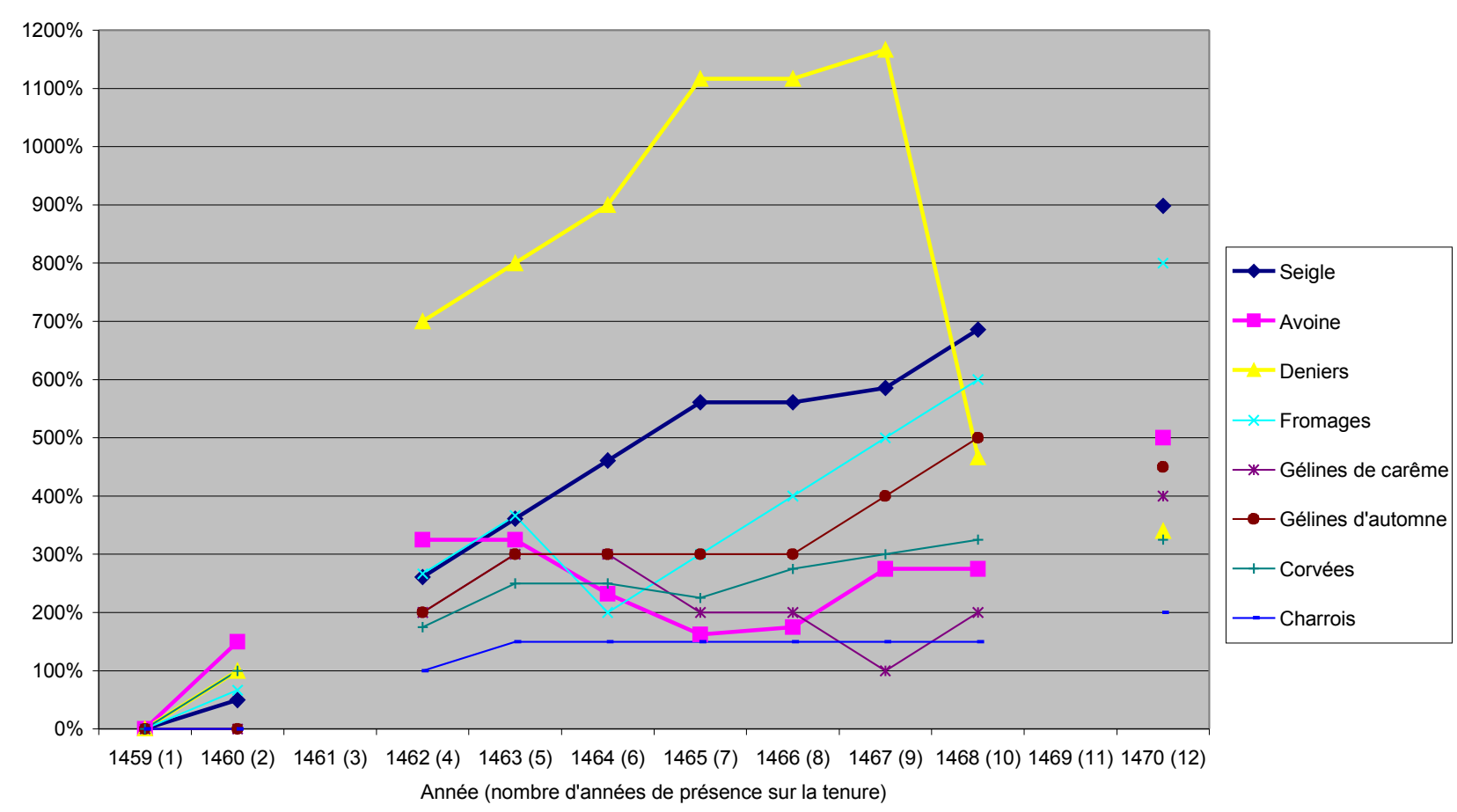

Graphique 4 : Durée de la possession d'une tenure achetée

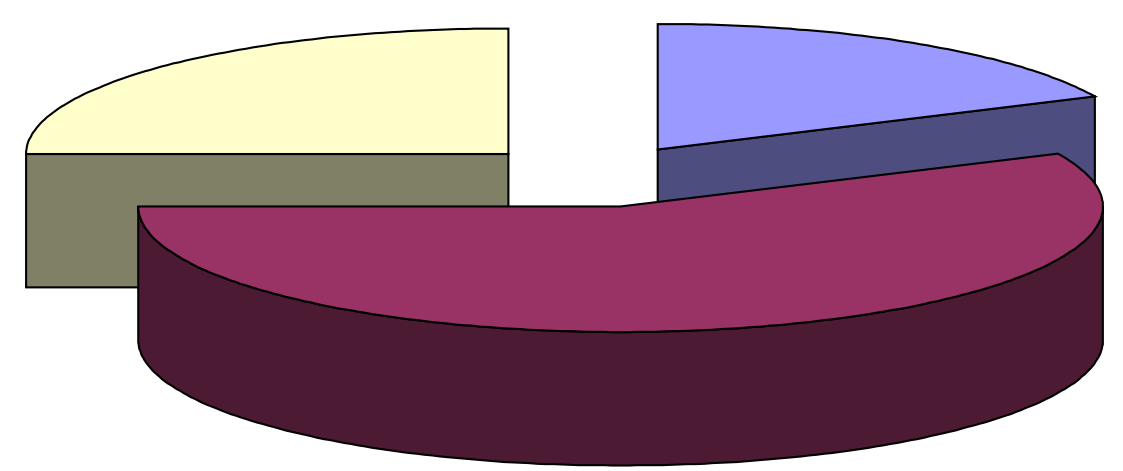




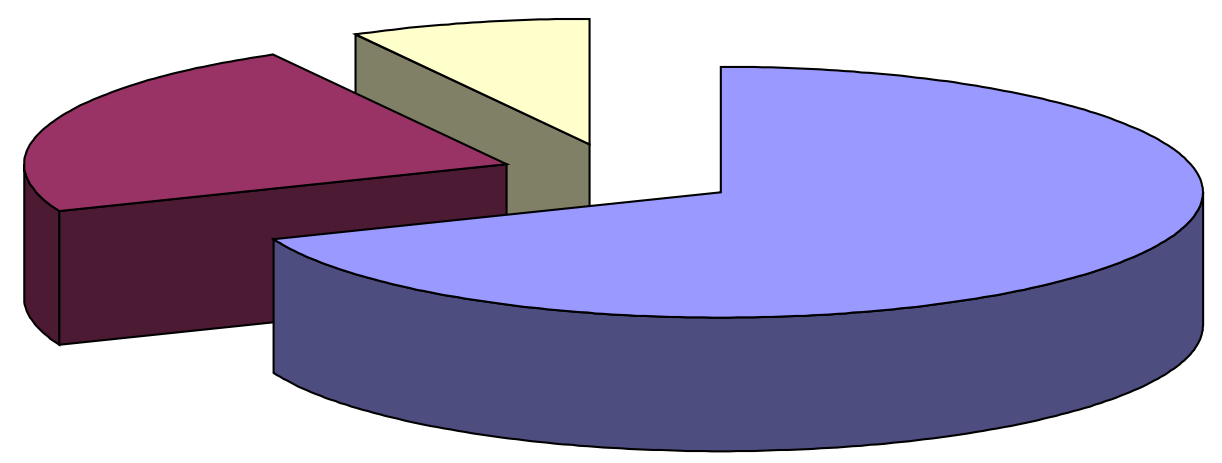

$\square$ Inférieure à 1 an

$\square$ De 1 à 9 ans

$\square$ Supérieure à 10 ans 